\title{
Políticas de ensino integral na América Latina
}

\author{
Andréa Giordanna Araujo da Silva \\ Universidade Federal de Alagoas
}

\section{Resumo}

O artigo apresenta a análise dos programas de ampliação do tempo escolar e diversificação curricular implantados em diversos países da América Latina, a partir da década de 1990, e objetiva identificar os resultados educacionais e sociais das políticas de ampliação do tempo escolar. A investigação utilizou, como fontes de pesquisa, documentos oficiais postos em circulação pelos governos de estados latino-americanos: Argentina, Chile, México, Uruguai, El Salvador, República Dominicana e Venezuela e identificou-se a existência de um confronto ideológico na definição dos fundamentos para a reestruturação dos sistemas de ensino público na América Latina. Observou-se que, de modo geral, a ampliação do tempo escolar e a diversificação das práticas curriculares têm como objetivos centrais promover a elevação do desempenho intelectual dos estudantes nos exames nacionais e internacionais de aferição de aprendizagem e garantir a qualificação da força de trabalho juvenil para o ingresso imediato no mercado

84 produtivo.

Palavras-chave: Ensino em tempo integral. América Latina. Políticas educacionais.

\section{Integral teaching policies in Latin America}

\section{Abstract}

The article presents the analysis of the programs of school time extension and curricular diversification implemented in several countries of Latin America, from the 1990s, and aims to the educational and social results of policies to extend school time. As research sources, the investigation used official documents circulated by the governments of Latin American states: Argentina, Chile, Mexico, Uruguay, El Salvador, Dominican Republic and Venezuela as sources of research and the existence of an ideological confrontation in the definition of the foundations for the restructuring of public education systems in Latin America. It was observed that, in general, the expansion of school time and the diversification of curricular practices have as their central objectives to promote the increase of the intellectual performance of students in national and international examinations of learning assessment and to ensure the qualification of the youth workforce for immediate entry into the productive market.

Keywords: Integral educacion. Latin America. Educational policies. 


\section{Políticas de enseñanza en tiempo integral en América Latina}

\section{Resumen}

El artículo presenta el análisis de los programas de ampliación del tiempo escolar y diversificación curricular implantados en diversos países de América Latina a partir de la década de 1990, teniendo como objetivo identificar los resultados educativos y sociales de las políticas de ampliación del tiempo escolar. La investigación utilizó como fuentes de investigación documentos oficiales puestos en circulación por los gobiernos de estados latinoamericanos: Argentina, Chile, México, Uruguay, El Salvador, República Dominicana y Venezuela y se identificó la existencia de un enfrentamiento ideológico en la definición de los fundamentos para la reestructuración de los sistemas de enseñanza pública en América Latina. Se observó que, en general, la ampliación del tiempo escolar y la diversificación de las prácticas curriculares tienen como objetivos centrales promover la elevación del desempeño intelectual de los estudiantes en los exámenes nacionales e internacionales de evaluación de aprendizaje y garantizar la calificación de la fuerza de trabajo juvenil para el ingreso inmediato en el mercado. Palabras clave: Escuelas de jornada ampliada. América Latina. Políticas educacionales.

\section{Introdução}

construto apresenta a descrição e a análise dos modelos de programas de ampliação do tempo escolar e diversificação curricular implantados em diversos países da América Latina: Argentina, Chile, México, Uruguai, El Salvador, República Dominicana e Venezuela. Para tanto, tem-se como "arquivo textual" - conjunto de "[...] documentos pertinentes e disponíveis sobre uma questão" (PÊCHEUX, 1994, p. 57) - os documentos oficiais postos em circulação por várias instituições e governos de estados latino-americanos.

Neste texto, consta parte dos resultados obtidos na pesquisa de doutorado desenvolvida no período de $2012-2016$. O estudo possibilitou identificar que existe um confronto ideológico na definição dos fundamentos para a reestruturação dos sistemas de ensino público na América Latina. Por um lado, se tem a ampliação do tempo escolar e a diversificação das práticas curriculares como eixos centrais das reformas políticas, visando à elevação do desempenho intelectual dos estudantes nos exames de aferição de aprendizagem e à qualificação mais imediata da força produtiva. Noutro caminho, tem-se a 
perspectiva de instituição dos fundamentos políticos e pedagógicos da educação integral como condição estrutural para as propostas político-pedagógicas escolares. Essa última constitui princípios e ideários confrontivos às políticas conservadoras, especialmente as que foram instituídas pelos governos latino americanos a partir da década de 1990. O ideário de educação integral tem como lócus os movimentos progressitas (movimentos sociais e sindicais) da América Latina e se inscreve em diferentes perspectivas político-ideológicas que buscam a emancipação econômica, política e cultural dos trabalhadores e dos grupos sociais marginalizados, especialmente por questões étnicas e raciais.

\section{O ensino (em tempo) integral: movimentos na América Latina}

As políticas nacionais de ensino de jornada ampliada e diversificação do currículo escolar, na América Latina, inserem-se em um contexto político e econômico mais amplo e se estabelecem afixadas a outras propostas políticas, como o compromisso Educação para Todos (EPT), instituído em 2000, na cidade de Dakar, no Senegal, entre governos de 164 países.

Também denominado de Marco de Ação de Dakar, o EPT constituiu-se 86 em um acordo coletivo entre diversos países na busca por melhores resultados das políticas educacionais, até o ano de 2015, e ficou definido que caberia à Unesco o trabalho de coordenar a atuação dos países. Ademais, participaram do evento como instituições proponentes de ações para o campo educacional: Banco Mundial, Programa das Nações Unidas para o Desenvolvimento (PNUD), Fundo de População das Nações Unidas (UNFPA) e Fundo das Nações Unidas para a Infância (Unicef).

No EPT, foram traçados os seguintes objetivos:

a) expandir e melhorar o cuidado e a educação da criança pequena, especialmente para as crianças mais vulneráveis e em maior desvantagem;

b) assegurar que todas as crianças, com ênfase especial nas meninas ecrianças em circunstâncias difíceis, tenham acesso à educação primária, obrigatória, gratuita e de boa qualidade até o ano 2015;

c) assegurar que as necessidades de aprendizagem de todos os jovens e adultos sejam atendidas pelo acesso eqüitativo à 
aprendizagem apropriada, a habilidades para a vida e a programas de formação para a cidadania;

d) alcançar uma melhoria de 50\% nos níveis de alfabetização de adultos até 2015 , especialmente para as mulheres, e acesso eqüitativo à educação básica e continuada para todos os adultos;

e) eliminar disparidades de gênero na educação primária e secundária até 2005 e alcançar a igualdade de gênero na educação até 2015, com enfoque na garantia ao acesso e o desempenho pleno e eqüitativo de meninas na educação básica de boa qualidade;

f) melhorar todos os aspectos da qualidade da educação e assegurar excelência para todos, de forma a garantir a todos resultados reconhecidos e mensuráveis, especialmente na alfabetização, matemática e habilidades essenciais à vida (DECLARAÇÃO DE DAKAR, 2000, grifos nossos).

Observa-se que a oferta obrigatória e universal da educação primária é o principal objetivo do programa e a atenção às "crianças mais vulneráveis e em maior desvantagem" ou "em circunstâncias difíceis"apresenta-se como aspecto importante para o alcance do acesso à educação como um direito. Ainda, a apropriação dos conteúdos curriculares de "resultados reconhecidos e mensuráveis, especialmente na alfabetização e matemática", definiria quais saberes e práticas deveriam ser tomadas como aprendizagens prioritárias a serem vinculadas pelos Estados nacionais na (re)organização das políticas educacionais e dos currículos escolares.

Cabe registrar que o mais importante Programa Internacional de Avaliação de Estudantes (Programme for International Studend Assessment-Pisa) é coordenado pela Organização para a Cooperação e Desenvolvimento Econômico (OCDE), cuja centralidade das ações está intrinsecamente demarcada pelas possibilidades de desenvolvimento econômico e estabilidade financeira dos 34 países que a constituem. Contudo, o único país da América Latina que é membro do organismo é o Chile, que se caracteriza como "[...] um laboratório de reformas educacionais" (SCHWARTZMAN, 2007, p. 22), de cunho neoliberal há quase cinquenta anos.

No movimento discursivo descrito, os enunciados sobre a ampliação do tempo escolar, de perspectiva assistencialista, mantêm uma forte ligação com a perspectiva de controle social, que se manifesta na ideia da escola como espaço capaz de prevenir a corrupção da mente e do corpo dos estudantes 
("com ênfase especial nas meninas") e de reduzir os efeitos da ausência de bens materiais mais imediatos como o acesso à alimentação e segurança ("crianças em circunstâncias difíceis"). Ainda, desde os anos 1990, o Banco Mundial (BM) vem financiando focalmente a "[...] educação das meninas, em razão, principalmente, de resultados de pesquisa que evidenciam relações positivas entre a educação da mulher-mãe e o bem-estar dos filhos" ICANDAU, 2013 , p. 35).

De outro modo, na VI Internacional de la Educación para América Latina, realizada em 2011 , para reafirmar os compromissos instituídos em Jomtiem (1990) e Dakar (2000), os representantes de instituições sindicais e organizações sociais de 166 países definiram entre as principais metas para a educação a serem atingidas até 2021: a promoção de uma educação pública de qualidade. Nesse evento, o estabelecimento da Educação Integral foi apontado como instrumento capaz de reestruturar a escola pública do processo de fragmentação sofrido com a implantação das políticas neoliberais das décadas de 1980 e 1990 (EDUCACIÓN..., 201 1). Nessa perspectiva, a expressão foi utilizada como sinônimo de resistência ao processo de fragmentação curricular e precarização das condições de trabalho no ensino público:

Al paradigma de la concepción humanista que privilegiaba a la educación pública como espacio democratizador y de integración social se impuso otro sustentado por la economía y una visión neoliberal que sobrepone lo privado por sobre lo público y privilegia las concepciones de mercado por sobre la democracia (EDUCACIÓN..., 2011 , p. 1).

Para a federação internacional, as práticas governamentais de tendência neoliberais financiadas por diferentes organismos internacionais - BM e Banco Interamericano de Desenvolvimento (BID) - provocaram "[...] reformas regresivas que deterioraron la educación pública impactando negativamente su calidad" (EDUCACIÓN..., 201 1 , p. 1). Logo, a educação integral é apresentada como ferramenta, capaz de confrontar as experiências formativas de perspectiva economicista e projetar uma sociedade mais igualitária:

Aspiramos a formar sociedades con personas que superen las tendencias individualistas, competitivas y consumistas imperantes. A formar seres humanos integrales, poseedores de conocimientos, valores y prácticas, que le permitan comprender, analizar y resolver 
los desafíos de la actual sociedad, un sujeto completo que no descuide la práctica deportiva, con amplia sensibilidad para apreciar todas las manifestaciones artísticas, que incorpore la sana recreación como una forma de plenitud humana.

Queremos ayudar a desarrollar personas integradas en sus comunidades, orgullosas de sus raíces, identidades locales, regionales y nacionales, capaces de aportar a la construcción de un mundo mejor, más justo, más equitativo y sin violencia (EDUCACIÓN..., 2011 , p. 4).

Na perspectiva do Banco Mundial (2007, 2007a, 201 2), que tem definido diretrizes para o ensino e o desempenho das escolas na América Latna, e já que, em 1998, financiava a implantação de escolas de jornada ampliada no Uruguai, a expansão do tempo escolar representa maiores custos para os cofres públicos, mas pode favorecer o desempenho cognitivo dos estudantes mais pobres:

Ampliar el número de escuelas de tiempo completo es costoso, aunque el impacto sobre aprendizaje es positivo y su impacto en el espacio fiscal del país sería moderado. El aumento de la cobertura de las escuelas de tiempo completo a 100.000 niños representaría un costo anual de por encima de US\$9 millones. El impacto estimado del programa es mayor en las escuelas con contexto más desfavorable, lo que apuntaría a la necesidad de focalizar la expansión a estos 100.000 estudiantes, sobretodo dado el alto costo del programa. Finalmente, la formación en servicio representa un costo moderado, aunque su impacto en los aprendizajes de los alumnos no ha sido documentado empíricamente. Esto apoyaría la necesidad de realizar una evaluación del impacto de la formación en servicio para poder optimizar el programa (BANCO MUNDIAL, 2007, p. 49-50).

Considerando os procedimentos apontados pelo Banco Mundial, - Uruguai, em 2011 , iniciou a implantação do Programa Aprender, Tiempo Completo y Tiempo Extendido em 285 escolas primárias, visando promover a equidade e qualidade da escola primária no país. Naquele momento, existiam dois programas especiais em desenvolvimento que buscavam enfrentar a vulnerabilidade sociocultural dos estudantes por meio da constituição de práticas pedagógicas inovadoras: as escolas de contexto crítico (2005) e o Programa 
de Maestros Comunitários (PMC), associados ao programa de ampliação do tempo escolar com o objetivo de:

[...] repensar el modelo escolar vigente, propicia el desarrollo en cada escuela de una propuesta pedagógica integral que se adecúe a las necesidades y potencialidades de cada uno de sus alumnos. Una escuela que sea capaz de desarrollar un proyecto institucional que promueva la participación genuina de todos los actores, donde se habiliten nuevos espacios de diálogo con la comunidad, posibilitando la revinculación con las escuelas de las familias; donde operen diversas alternativas para el desarrollo profesional de los docentes; donde se concreten las articulaciones institucionales que permitan que la escuela no enfrente sola las complejas situaciones de vulnerabilidad de sus alumnos y sus familias (FLORIT, 2012, p. 12, grifo nosso).

Segundo o estudo efetivado por Llambí, Perera e Piñeyro (2010) sobre a modalidade de ensino no país, a ampliação do tempo resultou no investimento de $78,6 \%$ a mais que o valor gasto com a escola parcial. Porém, os $80 \%$ desse aumento referem-se ao incremento da remuneração do professor 90 e aos gastos com a formação continuada. Ambas são condições estruturais fundamentais à melhoria do ensino público, de tempo parcial ou ampliado.

Para o ensino secundário, o foco do discurso oficial está na tipologia e operacionalização do currículo que deve ser ofertado aos jovens. Não se expõe a intenção de reconfiguração no modelo de financiamento:

La educación media debe contribuir a la formación integral, propiciar los procesos de socialización, la construcción de proyectos vitales, estimulando en los estudiantes, la valoración y el gusto por el conocimiento y la capacidad de explorar y aplicar el mismo combinando el trabajo individual y el trabajo en equipo. En este nivel, es impostergable, conjugar las tradiciones de la enseñanza secundaria y la enseñanza técnica y tecnológica, diseñando articulaciones entre las distintas formaciones, y promoviendo una educación integral (URUGUAY, 2014, p. 6).

Na República Dominicana, o programa de ampliação da jornada escolar (Programa de Jornada Extendida) iniciou-se, em novembro de 2011 , como projeto piloto em 21 escolas que ofertam o primeiro e segundo ciclos de ensino, que estavam localizadas em áreas urbanas e rurais onde as 
populações apresentavam elevados graus de vulnerabilidade social. No período da manhã, as práticas pedagógicas buscam atingir as metas do currículo oficial, e, no período da tarde, são desenvolvidas atividades para reforçar a aprendizagem dos conteúdos das disciplinas nucleares e clássicas.

Em 2012, o Ministério da Educação do país e o Banco Mundial, em conjunto, contrataram uma empresa de consultoria para realizar um estudo, em 10 escolas, a fim de verificar os efeitos da ampliação do tempo sobre a aprendizagem dos estudantes. Alguns dos principais resultados apontados foram:

a. En la mayoría de las escuelas visitadas hay problemas con la organización e identificación del horario escolar. En las escuelas de jornada ampliada, los directores aun realizan ajustes para integrar al horario escolar las actividades adicionales y a los nuevos docentes o tutores (también denominados monitores). En las escuelas de jornada tradicional, donde no han habido cambios recientes, los directores no cuentan con un esquema de organización e identificación de horarios eficiente y esto en algunos casos retrasó la identificación y selección de las clases a observar.

b. En general, se observó que hay un considerable número de días de suspensión de las actividades académicas en las escuelas. Primeramente, no se pudieron realizar visitas el 14 de febrero debido a que la mayoría de las escuelas habían suspendido las actividades académicas normales y realizaron festivales. Asimismo, el 17 de febrero, la escuela visitada por la mañana tenía programado un festejo para celebrar el día del estudiante y como resultado de la notificación de la visita de observación fue reprogramado y se impartieron clases normalmente; en ese mismo día la escuela programada para la visita por la tarde suspendió la jornada completa y no fue posible visitarla. Posteriormente, el 22 de febrero la escuela visitada por la tarde tenía programadas actividades de preparación para el carnaval en todas las clases, ante esto, el personal del Ministerio solicitó se impartieran clases de forma tradicional. No obstante, se presentaron dos sacerdotes a realizar una ceremonia religiosa en la escuela y se suspendió una parte de la jornada escolar.

c. En la mayoría de las escuelas de jornada tradicional se observó que la duración de jornada (4 horas) difícilmente se cumple. En algunas de las escuelas visitadas, había padres a la salida de la escuela antes del horario oficial de término de la jornada; en otros casos los estudiantes mencionaron que como resultado de la visita 
habían permanecido más tiempo en la escuela, y en otros casos se observó que los docentes llegaban tarde a la escuela.

d. En prácticamente todas las clases observadas, se observó una baja calidad en las técnicas de enseñanza por parte de los docentes. Así como también, en casi todos los casos, se observó un grado de complejidad muy básico en los contenidos expuestos en las clases.

e. En algunos casos, se observaron importantes deficiencias en el desempeño académico de los estudiantes; por ejemplo, estudiantes de tercer grado que no leen y estudiantes de octavo grado que copian muy lentamente del pizarrón al cuaderno e impidiendo al docente continuar con otra actividad.

f. En las escuelas de jornada ampliada se observó un ambiente escolar más positivo y de comunicación efectiva entre los docentes y los directivos en comparación con las escuelas de jornada tradicional. Asimismo, los docentes mostraron tener una relación más cordial y afectiva con sus estudiantes en comparación con los docentes de las escuelas de jornada tradicional.

g. El programa de escuelas de jornada ampliada es un conjunto de múltiples intervenciones que ha beneficiado a una muestra de escuelas. En dichos establecimientos no solo se ha invertido en ampliar la jornada escolar utilizando más recursos para el pago del tiempo extra de los docentes o contratación de nuevos docentes, sino también se han ofrecido cursos de capacitación a docentes y directivos, se han invertido recursos en el mejoramiento del equipamiento e infraestructura de los planteles y se proveen alimentos para el desayuno y la comida ofrecida a los estudiantes, entre otros (THE WORLD BANK, 2012, p. 9-1 1, grifos nossos).

Observa-se que o ideário de introdução de práticas educativas diversificadas e de uma jornada escolar mais ampla apresenta-se como programa político, capaz de promover a reordenação do ensino público, porém está sustentada por um "[...] conjunto de múltiples intervenciones" que têm como principais mediadores a ampliação dos recursos estruturais e pedagógicos e do número de professores, associada à oferta de cursos de formação (THE WORLD BANK, 2012 , p. 10).

É preciso registrar que, embora a pesquisa afirme ter existido progresso no desempenho profissional dos professores em virtude do aumento da jornada escolar, o estudo não apresenta nenhum resultado consistente que 
demonstre ter havido avanços no desempenho intelectual (maior aquisição de saberes e práticas acadêmicos) dos estudantes.

Em El Salvador, em 2011 , implantaram-se 22 escolas. Como projeto piloto, o Programa Escuelas Inclusivas de Tiempo Pleno (EITP) passou a ser desenvolvido com o apoio financeiro da United States Agency for International Development (USAID) - Agência dos Estados Unidos para o Desenvolvimento Internacional -, do Banco Mundial da Cooperação Italiana, da Organização Internacional do Trabalho (OIT), entre outros cooperantes. O modelo pedagógico deu origem aos Sistemas Integrados de Escuelas Inclusivas de Tiempo Pleno (SIEITP), que estão destinados:

La diversidad del estudiantado con sus estilos, necesidades, características y ritmos de aprendizaje requieren de uma atención diferenciada para lograr su desarrollo integral. Es por ello que el modelo pedagógico expresa una postura activa para revertir el ciclo vicioso de marginación social-fracaso escolar, y propone superarlo con una escuela inclusiva (EL SALVADOR, 2013, p. 10).

Destarte, pela diversidade do público que atende, o programa apresenta a flexibilidade curricular como o principal elemento para promoção de práticas pedagógicas inclusivas e busca, na associação com outras instituições sociais, culturais e empresariais a solução para o desenvolvimento das atividades curriculares diversificadas em consonância com os interesses e necessidades dos estudantes.

Mesmo sem ter passado por qualquer processo avaliativo sistemático, em 2014, o programa já havia sido incorporado por 2.285 escolas, e o governo central o apresentava como modelo ideal de educação integral, que seria capaz de originar qualidade no ensino público por meio de "[...] aprendizajes pertinentes, participación de la comunidad, articulación territorial de centros escolares y prevención de la violencia, entre otros componentes" (ALVARADO, 2014, s/p.).

O programa atende a todos os níveis da educação básica e tem como critério principal de adesão que as escolas estejam situadas em "[...] zonas con un alto índice de pobreza y uma mayor incidencia de violência" e a jornada ampliada seja utilizada para o desenvolvimento de "[...] actividades lúdicas, culturales, educativas y deportivas" (ALVARADO, 2013,s/p.). 
A reflexão em torno da escola pública como espaço formativo que reconheça os alunos como coletivo social, não como indivíduo, parece representar a tentativa de (re)formulação e análise crítica e política sobre o papel social da escola. Todavia, a estrutura e o objetivo social e político da escola pública, normalmente, não são objetivamente reformulados considerando-se os contextos socioeconômicos e culturais, além da percepção de condição de vulnerabilidade social dos alunos das escolas públicas.

Também em 201 1, o México lançou o programa de reforma da educação-Reforma Integral de la Educación Básica -, e a ampliação do tempo escolar começou a fazer parte da estrutura oficial do sistema de ensino do país. A partir de então, as unidades de ensino passaram a ser divididas em três categorias temporais: meio tempo, tempo ampliado e tempo completo. Nesse quadro, as escolas de nível fundamental (denominadas de primárias e secundárias) de jornada completa passaram a oferecer 35 e 45 horas de atividades semanais respectivamente. Já as unidades de ensino médio de formação técnica, começaram a ofertar 50 horas de atividades por semana IGAMBOA MONTEJANO; GUTIÉRREZ SÁNCHEZ, 20121.

$\bigcirc$ programa curricular é nacional e comum a todas as escolas, 94 atende, portanto, aos diferentes níveis e modalidades de ensino, sendo estruturado pela inclusão de disciplinas fixadas na grade curricular das instituições de ensino. Em El Salvador, o principal objetivo do programa é elevar o rendimento estudantil e reduzir a vulnerabilidade sociocultural dos estudantes.

Apesar de o programa não haver apresentado resultados positivos nas avaliações de desempenho estudantil e gestor, o país realizou, em 2015, um empréstimo de 350 milhões de dólares com o Banco Mundial para ampliar, no prazo de quatro anos, os programas Escuelas de Calidad e de Escuelas de Tiempo Completo (EL BANCO..., 2015).

No México, o Bachillerato, ou escola média superior (EMS), é o nível de ensino ofertado aos jovens entre 15 e 17 (e/ou 18 e 19) anos, e está subdividido em três modalidades: Bachillerato General, Educación Profesional Técnica e Bachillerato Tecnológico. Esse nível de ensino, passou, em 2008, por uma expressiva reforma, e a nova diretiva política não tratou da jornada escolar como objeto expressivo de discussão no texto oficial, mas reconfigurou a forma de operacionalização dos currículos das modalidades de ensino para atender às demandas imediatas de formação dos jovens, relacionadas com o 
campo laboral. Desse modo, a origem socioeconômica e cultural dos estudantes foi o principal alicerce do discurso governamental:

Quienes ingresan a la EMS tienen intereses y necesidades diversas en función de los cuales definen sus trayectorias escolares y laborales: para algunos éste es el último tramo en la educación escolarizada, para otros es el tránsito a la educación superior. En ese sentido, la escuela debe ofrecer las opciones necesarias para que los jóvenes satisfagan sus expectativas de preparación universitaria, laboral o ambas, según sea su interés.

La diversidad de preferencias profesionales y académicas, y la comprensión de que, para el caso de nuestro país, los jóvenes de la EMS se encuentran en edad laboral, debe reflejarse en la estructuración de planes de estudio flexibles. Hasta donde sea razonable, debe dejarse abierta la posibilidad de elegir itinerarios escolares propios, con el menor número posible de secuencias obligatorias.

Además de ser pertinente a las necesidades personales aquí planteadas, la EMS debe ser relevante desde el punto de vista social. Esto significa que el fortalecimiento del nivel debe colocar a las regiones y al país en mejores condiciones de desarrollo. La posibilidad de obtener ventajas en los mercados mundiales y nacionales radica en buena medida en la formación de personas que puedan participar en la sociedad del conocimiento: sólidas bases formativas, capacidad para aprender de forma autónoma a lo largo de la vida, y habilidades para resolver problemas y desarrollar proyectos, entre otros.

Algunos subsistemas de la EMS ya han comenzado a adaptarse a estas realidades y retos mediante la puesta en práctica de reformas curriculares específicas a cada caso (MÉXICO, 2008, p. 22-23, grifos nossos).

A discussão central, em torno da qualidade do ensino público, não consiste em ampliar as práticas curriculares ou o tempo escolar, mas em possibilitar a constituição de um programa curricular flexível e capaz de se adequar, permanentemente, à volatilidade do mercado de trabalho. Nessa perspectiva, a formação integral dos estudantes está definida como a "[... ] capacidad para aprender de forma autónoma a lo largo de la vida, y habilidades para resolver problemas y desarrollar proyectos, entre otros" (MÉXICO, 2008, p. 23, grifo nosso). 
A reforma do Bachillerato mexicano apresenta aspectos do paradigma economicista que deu sustentação às políticas educacionais desenvolvidas no Brasil, na década de 1990, e, no Chile, desde a década de 1970, inspiradas pelos princípios liberais, que apontavam o produtivismo e a meritocracia como meios e fins da educação pública, e apostava na privatização como ferramenta capaz de (re)qualificar o ensino público. Como consequência, na década de 1980, a participação do ensino privado abrangia 40\% das matrículas da educação básica do Chile.

Nesse processo, mais de 12\% das escolas secundárias do Chile, de caráter técnico-profissional, administradas pelo governo federal, foram transferidas para as corporações de empresários. $O$ resultado foi uma forte presença do setor empresarial na definição das diretrizes do ensino primário e secundário. Cabe salientar que, em 2002, as escolas particulares subsidiadas pelo estado ofertavam 37,8\% das matrículas da educação básica (SCHWARTZMAN, 2007).

Com o fim do regime militar no Chile, em 1990, o novo governo (Concertación de Partidos por la Democracia) iniciou uma série de reformas a fim de aumentar o financiamento do Estado na educação, porém a estrutura tipológica e operacional das instituições de ensino não sofreu grandes alterações (CUNHA, 2000). A perspectiva gerencial, desenvolvida por duas décadas, permaneceu, e foi, nesse cenário, que se instituiu o processo de ampliação da jornada escolar, tendo como objetivo a reforma da educação básica, visando:

(i) [...] mejorar los aprendizajes: ya que se reconoce el mayor tiempo es un factor que afecta positivamente al aprendizaje, el trabajo técnico de los docentes y la gestión de cada establecimiento. (ii) Para lograr mayor equidad en la educación: ya que la JEC permitirá atender a la población de alto riesgo social y educativo, y al mismo tiempo es una acción que iguala las oportunidades de aprender al aumentar de manera significativa el tiempo de trabajo escolar a todos los estudiantes de establecimientos educacionales subvencionados por el Estado y no sólo a un sector minoritario y privado como había sido hasta entonces (GARCÍA-HUIDOBRO; CONCHA, 2009, p. 4).

Ainda segundo García-Huidobro e Concha, no campo social, a ampliação da jornada escolar pretendia também promover: 
El cuidado de los niños y jóvenes habida cuenta de la necesidad de aumentar el trabajo femenino en los sectores más pobres de la población5 y el aumento del espacio social, recreativo, cultural y deportivo en las poblaciones urbanas y sub-urbanas pobres densamente pobladas, al existir después de las cinco de la tarde un conjunto de establecimientos que pueden quedar liberados para la comunidad, lo que no sucedía cuando estos funcionaban en doble jornada (GARCÍA-HUIDOBRO; CONCHA, 2009, p. 4).

A implantação do ensino de tempo ampliado e a reconfiguração do currículo escolar no Chile resultam de um amplo movimento social e de professores que reivindicavam reformas no campo educacional, mas também do interesse corporativo do setor empresarial. Sendo assim, estabeleceram-se quatro eixos indutores da Reforma Educacional Chilena: a) os Programas de Melhoramento e Inovação Pedagógica, cuja função era fornecer recursos didáticos e pedagógicos para as escolas a fim de propiciar melhores condições para as práticas de ensino, b) a Reforma Curricular, caracterizada pela constituição de um currículo nacional de base comum, c) o Desenvolvimento Profissional dos Docentes, que buscava a melhoria da formação dos professores mediante o estabelecimento de cursos de formação inicial e continuada realizados em parceria com as universidades públicas e privadas, especialmente para o aprofundamento das saberes dos campos disciplinares; d)Jornada Escolar Completa Diurna (JEC), que ampliou a jornada de ensino em escolas primárias e médias, públicas e particulares, subsidiadas pelo Estado.

Por conseguinte, a Lei Nacional de Educação Básica, lançada em 1996, determinava que, gradativamente, as escolas fundamentais e médias passariam a ser operacionalizados em 38 e 42 horas de atividades pedagógicas semanais respectivamente. Houve, portanto, um acréscimo de 5 e 6 horas na grade curricular nacional. Todavia, para serem incorporadas ao programa, as escolas deveriam apresentar algumas condições estruturais primordiais, que seriam, segundo a projeção do governo central, universalizadas para todo o sistema nacional de ensino no prazo de seis anos.

Logo, para aderir ao programa JEC, as unidades de ensino deveriam elaborar e enviar para avaliação e aprovação do Ministério da Educação um projeto de reformulação curricular e de ampliação da jornada. As práticas criadas deveriam ter como objetivo principal possibilitar a melhor apropriação dos conteúdos das disciplinas clássicas e elevar o desempenho dos alunos 
nos exames de verificação de aprendizagem. Ainda, as instituições de ensino deveriam ter as condições infraestruturais e os equipamentos pedagógicos adequados para o atendimento dos alunos e garantir, formalmente, o tempo pedagógico complementar, despendido para o trabalho técnico e pedagógico dos professores.

Embora o Ministério de Educação chileno tenha avaliado a implantação do JEC como política positiva para o sistema de ensino do país e para a formação e segurança das crianças e jovens, pois ficavam sob a tutela da escola enquanto os pais estão trabalhando, as apreciações avaliativas não capturam melhorias significativas em áreas específicas de aprendizagem, a exemplo de linguagem, matemática e ciência. Os acréscimos de desempenho observados estavam diretamente relacionados com o tipo de escola que o aluno frequentava (municipal estatal, privada subsidiada ou particular), com o tipo de ingresso na instituição de ensino, com ou sem prova de seleção, as condições socioeconômicas e culturais dos pais e a capacidade e limitação financeira dos municípios (BLOQUE SOCIAL, 2006; GARCÍA-HUIDOBRO; CONCHA, 2009). Ainda, segundo o documento La crisis educativa en Chile: diagnóstico y propuestas, produzido pelo Bloque Social, em dezembro de 98 2006:

Las reformas curriculares y programas especiales desarrollados por los gobiernos de la Concertación para generar una educación de calidad no han tenido éxito. Lo objetivo es que hoy no existe una educación integral, y que la supuesta calidad se establece sólo a partir de los peores o mejores resultados del SIMCE, que sólo dan cuenta de los rendimientos en determinados contenidos y competencias de algunas áreas del Curriculum.

Son estos contenidos del SIMCE lo que se refuerza en cada una de las escuelas y liceos, incluso en las horas de Jornada Escolar Completa, que supuestamente debieran servir justamente para una formación integral y mejor desarrollo del sujeto (BLOQUE SOCIAL, 2006, p. 5).

A análise do enunciado do Bloque Social (2006) propicia desvelar que a ampliação do tempo escolar não promoveu melhorias na formação oferecida pelas escolas chilenas porque o principal objetivo do Programa era atender a exigências externas às escolas e distantes das biografias e demandas socioculturais dos estudantes. 
Segundo Santomé (2013, p. 47), "[... ] o controle da produção, orientação e utilização e distribuição do conhecimento está claramente marcado pela origem do financiamento". No caso do Chile, embora o Estado fosse o maior financiador das escolas, o setor empresarial assumiu a função de produzir e administrar as práticas e os conteúdos do currículo escolar e de definir o que seria um sistema de ensino eficaz e um estudante qualificado.

É possível observar, por meio das experiências políticas analisadas, especialmente a chilena, que a ampliação das atividades curriculares e da jornada escolar não é sinônimo de reformulação paradigmática, porque a ampliação da carga horária de atividades nas escolas, assim como a criação de práticas pedagógicas, podem ser apenas instrumentos para reforçar ou consolidar uma perspectiva política sobre a função social da escola.

Destarte, no cenário latino-americano, a Venezuela parece ser um dos poucos países - além de Cuba - que observam a educação integral, no discurso oficial, como concepção político-pedagógica estrutural para todos os níveis e modalidades de ensino da educação básica, não apenas como um modelo operacional. Pois,

El Proyecto Escuelas Bolivarianas constituye una política del Estado Venezolano, dirigida a brindar una educación integral, de calidad, a niños, niñas y adolescentes en los niveles de preescolar y básica de I y || Etapa, afrontando las deficiencias presentadas en dichos niveles. El proyecto se inscribe en el proceso de transformación política y social que vive el país y responde a la alta prioridad que se le otorga a la educación como eje fundamental para la transformación social dentro de este proceso.

[...]

La nutrición, la salud, el deporte, la recreación, la cultura, el maestro como líder y constructor social, la recuperación ambiental del espacio escolar, forman parte del concepto de calidad educativa (REPÚBLICA BOLIVARIANA DE VENEZUELA, 2003, p. 4, 19).

Sendo assim, o Projeto Piloto Escuela de Tiempo Completo (ETC) apresenta-se como elemento estrutural para uma nova proposta social. É importante esclarecer que existe um forte movimento pelo reconhecimento da diversidade das etnias indígenas do país e, por isso, as comunidades exercem grande influência sobre a composição do currículo escolar. "De tal forma que todas las actividades son consideradas curriculares y su distribución en la carga horaria 
responde a la planificación que el conjunto de docentes, alumnos y comunidad consideren pertinentes" (REPÚBLICA BOLIVARIANA DE VENEZUELA, 2003, p. 20).

No caso do ensino médio, a formação técnica é apontada como demanda socioeconômica imediata e como recurso necessário ao desenvolvimento do país. Nesse sentido, a orientação do Estado é para que as unidades de ensino desenvolvam seus projetos educativos, considerando as necessidades do cenário produtivo local e nacional.

É importante esclarecer que a Venezuela, desde 2005, tem sido o principal país da América Latina a contrair empréstimos com a China, reduzindo, portanto, a influência das agências multilaterais, BM e BID, na regulamentação de suas políticas sociais, uma vez que o principal interesse da China está em garantir a produção e compra de combustível. Logo, as normas de crédito estão focalizadas na implantação e no desenvolvimento de projetos de mineração e energia e a credora não fixa medidas intervencionistas aos países devedores. Sendo assim, "[...] em geral, os países com governos de esquerda preferem recorrer à China e evitar, assim, a imposição de políticas neoliberais" (CASAS MANZANO, 2015). O efeito disso no campo educacional é que a atenção das práticas escolares pode estar mais voltada para atender

100 às demandas sociais e produtivas das comunidades do país e menos para apresentar, em curto prazo, saldos mais positivos na realização dos exames de avaliação de desempenho estudantil de âmbito internacional. Esse movimento pode constituir-se como de resistência aos efeitos das políticas educacionais implantadas no país, na década de 1990, fortemente influenciadas pelo ideário neoliberal (MELO, 2004).

Observa-se que a ampliação do tempo escolar tem sido apresentada por governos de diversos países como estratégia técnica e política para melhoria da educação básica ofertada, de modo geral, às comunidades mais pobres. De certo modo, a constituição das escolas em jornada ampliada é um avanço porque retoma, mesmo de forma restrita, a discussão de que as problemáticas surgidas nos processos de ensino-aprendizagem não estão relacionadas unilateralmente com as potencialidades individuais do sujeito aprendiz. 


\section{Considerações Finais}

Nos diversos países, os líderes governamentais assumem posições políticas e pedagógicas distintas, não existe um modelo universal para o estabelecimento da diversidade curricular e para a ampliação da jornada escolar, porém observam-se tendências. De modo geral, as práticas educativas seguem dois movimentos: ou buscam promover aprendizados que colaborem com o processo de adaptação das pessoas às circunstâncias socioprodutivas do capitalismo ou pretendem produzir relações sociais e saberes que possam favorecer o desenvolvimento de práticas políticas, econômicas e culturais mais igualitárias.

Entretanto, é preciso ter muita atenção na análise das propostas, porque as fronteiras políticas nem sempre são facilmente identificáveis, pois, mesmo idealizados mediante projetos políticos distintos, um objetivo comum aos programas de diversificação curricular e de ampliação da jornada escolar, desenvolvidos na América Latina, é reduzir o índice de crianças e jovens vítimas de violência; e beneficiar os estudantes com os cuidados básicos lofertar atendimento nutricional adequado, desenvolver hábitos de promoção e proteção à saúde e ampliar as experiências culturais e formativas, que estejam em consonância com os valores e princípios da sociedade). lgualmente, facilitar o ingresso e/ou permanência dos pais e/ou responsáveis pelos estudantes no mercado de trabalho, sobretudo a força de trabalho feminina.

Dessa forma, as políticas de ampliação da jornada e diversificação do currículo escolar são usualmente defendidas, nos campos político e acadêmico, como práticas de discriminação positiva (RODRÍGUEZ CARRILLO, 20 1 2) ou como política de ação afirmativa que pretende o enfrentamento das desigualdades sociais (LECLERC; MOLL, 2012).

Contudo, uma condição central das ações afirmativas é que se trata de uma política focal que aloca "[... ] recursos em benefício de pessoas pertencentes a grupos discriminados e vitimados pela exclusão sócio-econômica no passado ou no presente" (GEMAA, 2011 , s/p.). Assim, uma política voltada à reestruturação do currículo da escola pública, que atende a maior parte das crianças e jovens em idade escolar, não pode ser tratada como "medida corretiva". 
As políticas de ampliação da jornada escolar e de diversificação curricular só poderão apresentar melhorias reais para os sistemas de ensino, dos países latino-americanos, se estiverem associadas a outras políticas que promovam a melhoria das condições de trabalho, moradia e de acesso ao patrimônio cultural aos familiares dos estudantes. De outra forma, serão sempre experiências-modelo que servem como vitrine para captação do apoio popular aos regimes políticos temporários, como os mandatos governamentais da maioria das repúblicas democráticas latino-americanas.

Verifica-se ainda que, quanto maior o financiamento e a aproximação da proposta política com as agências internacionais de fomento, menor a liberdade política e pedagógica dos sistemas de ensino e das escolas. Desse modo, é imperativo que as políticas de reestruturação do escolar sejam financiadas unicamente com recursos obtidos mediante os rendimentos resultantes da produtividade dos setores econômicos do próprio país.

Observa-se, portanto, que a maior parte das propostas educacionais de ampliação da jornada escolar na América Latina está direcionada ao público que frequenta o ensino fundamental, na perspectiva de garantir a elevação do nível de escolarização e a proteção social das crianças. Para

102 o ensino médio, a inclusão da formação profissional é o que determina, na maioria dos casos, o interesse pela diversificação das práticas curriculares e ampliação do tempo escolar.

\section{Referências}

ALVARADO, Teresa. Así funciona el modelo de Escuela Inclusiva. Transparencia Activa, San Salvador, 30 maio 2013. Disponível em: http://www.transparenciaactiva.gob.sv/asi-funciona-el-modelo-de-escuela-inclusiva/. Acesso em: 25 abr. 2015.

Programa de Escuelas a Tiempo Pleno se extiende a 2,285 centros educativos. Transparencia Activa, San Salvador, 25 jul. 2014. Disponível em: http://www. transparenciaactiva.gob.sv/programa-de-escuelas-a-tiempo-pleno-se-extiende-a-2285-centros-educativos/. Acesso em: 25 abr. 2015.

BANCO MUNDIAL. Uruguay: equidad y calidad de la educación básica 2007 documento del Banco Mundial. Informe n. $38.082,9$ mar. 2007. Disponível em: hitp://www-wds. worldbank.org/external/default/WDSContentServer/WDSP/IB/2007/10/24/00031 
0607 20071024104856/Rendered/PDF/380820UYOEducacionOwhiteOcoverO 1PUB LIC 1.pdf. Acesso em: 14 jun. 2015.

\section{Ampliar oportunidades y construir competências para los jóve-} nes: una nueva agenda para la educación secundaria. Washington: DC, 2007a. Disponível em: http://siteresources.worldbank.org/EDUCATION/ Resources/278200-1099079877269/547664-1099079967208/Expending_opportunities_secondary_Spanish.pdf. Acesso em: 31 jul. 2017.

Desconectados: habilidades, educación y empleo en América Latina. Washington: DC, 2012. Diponível em: http://www.redetis.iipe.unesco.org/publicaciones/ desconectados-habilidades-educacion-y-empleo-en-america-latina-washington-banco-interamericano-de-desarrollo-bid/\#.WX-ol 1WGPIU. Acesso em: 31 jul.2017.

EL BANCO Mundial señala regresión educativa en México. El Sol de Nayarit, 15 abr. 2015. Disponível em: http://www.elsoldenayarit.mx/cultura/34132-el-banco-mundial-senala-regresion-educativa-en-mexico. Acesso em: 26 abr. 2015.

BLOQUE SOCIAL. La crisis educativa en Chile: diagnóstico y propuestas. Dic. 2006. Disponível em: http://opech.cl/bibliografico/calidad_equidad/Documento_Bloque_ Social_Noviembre.pdf. Acesso em: 9 jul. 2016.

CANDAU, Vera Maria. Reformas educacionais hoje na América Latina. In: MOREIRA, Antonio Flávio Barbosa. Currículo: políticas e práticas. Campinas: Papirus, 2013.

CASAS MANZANO, Alba.Os empréstimos da China à América Latina crescem 22 bilhões de dólares. El País, Economia, Madri, fev. 2015. Disponível em: http://brasil.elpais. $\mathrm{com} / \mathrm{m} /$ brasil/2015/02/27/economia/1425072766_388301.html. Acesso em: 26 abr. 2015.

CUNHA, Luiz Antonio. Ensino médio e ensino técnico na América Latina: Brasil, Argentina e Chile. Cadernos de Pesquisa, São Paulo, n. 111 , p. 47-69, dez. 2000.

DECLARAÇÃO DE DAKAR 2000. Educação para todos: texto adotado pela Cúpula Mundial de Educação. Dakar, 2000. Disponível em: http://www. direitoshumanos.usp.br/index. php/Direito-a-Eduda\%C3\%A3o/declaracao-de-dakar.html. Acesso em: 17 jan. 2014.

EDUCACIÓN integral: el desafío para una lberoamérica con enfoque social. In: INTERNACIONAL DE LA EDUCACIÓN PARA AMÉRICA LATINA, 2011. Disponível em: http://www.ei-ie-al.org/declaraciones/100910iberoamerica.pdf. Acesso em: 17 jan. 2014. 
EL SALVADOR. Elementos para el desarrollo de modelo pedagógico del sistema educativo nacional: versión final. San Salvador: Ministerio de Educación, 2013.

FLORIT, Héctor. Prólogo del Consejo de Educación Inicial y Primaria. In: MANCEBO, María Ester; ALONSO, Cecilia. Programa Aprender de Uruguay: las visiones y opinionesde los maestros y diretores. Montevideo: Unicef, 2012. p. 9-12. Disponível em: http://www.unicef.org/uruguay/spanish/aprender-web.pdf. Acesso em: 17 jan. 2014

GAMBOA MONTEJANO, Claudia; GUTIÉRREZ SÁNCHEZ, Miriam. Planes y programas de educación básica en México: estudio teórico conceptual, de antecedentes, iniciativas presentadas en la LXI legislatura y derecho comparado. México, DF: Dirección General de Servicios de Documentación, Información y Análisis, 2012. Disponível em: http://www. diputados.gob.mx/sedia/sia/spi/SAPI-ISS-56-12.pdf. Acesso em: 22 abr.2015.

GARCÍA-HUIDOBRO, Juan Eduardo; CONCHA, Carlos. Jornada escolar completa: laexperiencia chilena. 2009. Disponível em: http://www.ceppe.cl/images/stories/recursos/ publicaciones/Carlos\%20Concha/Jornada-escolar-completa.-la-experiencia-chilena.pdf. Acesso em: 20 mar. 2015.

GEMAA. Grupo de Estudos Multidisciplinares da Ação Afirmativa. O que são ações afirmativas? Rio de Janeiro: Instituto de Estudos Sociais e Políticos, UERJ, 2011 . Disponível

104 em: http://gemaa.iesp.veri.br/dados/o-que-sao-acoes-afirmativas.html. Acesso em: 28 abr. 2015 .

LECLERC, Gesuína; MOLL, Jaqueline. Políticas de educação integral em jornada ampliada. Em Aberto, Brasília, v. 25, n. 88, p. 17-49, jul./dez. 2012.

LLAMBÍ, Cecilia; PERERA, Marcelo; PIÑEYRO, Leticia. Dimensionamiento económico de la extensión del tiempo pedagógico en educación primaria. Montevideo: Centro de Investigaciones Económicas, 2010.

MELO, Adriana Sales de Melo. A mundialização da educação: consolidação do projeto neoliberal na América Latina, Brasil e Venezuela. Maceió: EDFAL, 2004.

MÉXICO. Subsecretaría de Educación Media Superior de la Secretaría de Educación Pública de México. Reforma integral de la educación media superior en Mexico: la creación de un Sistema Nacional de Bachillerato en un marco de diversidad. México: 2008. Disponível em: http://idbdocs.iadb.org/wsdocs/getdocument.aspx?docnum=38043188. Acesso em: 22 abr. 2015.

PÊCHEUX, Michel. LER o arquivo hoje. In: ORLANDI, Erni (Org.). Gestos de leitura: uma história no discurso. Campinas: Editora da Unicamp, 1994. 
REPÚBLICA BOLIVARIANA DE VENEZUELA. Plan educación para todos Venezuela: balance nacional y programa de trabajo.Caracas: Ministerio de Educación, Cultura y Deportes, 2003.

RODRÍGUEZ CARRILLO, Fernando. Escuela Inclusiva vs Escuela de Tiempo Completo. In: BARRAZA MACÍAS, Arturo (Coord.). Modelos escolares contemporáneos: su abordaje a través de análisis comparativos. México: Instituto Universitario Anglo Español Posgrado, 2012.

SANTOMÉ, Jurjo Torres. Currículo escolar e justiça social: o cavalo de Troia da educação. Porto Alegre: Penso, 2013.

SCHWARTZMAN, Simon. Chile: um laboratório de reformas educacionais. In: SEMINÁRIO SOBRE A QUALIDADE DA EDUCAÇÃO BÁSICA Câmara dos Deputados: Brasília, 2007. (Promovido pela Comissão de Educação da Câmara dos Deputados).

THE WORLD BANK. Uso del tiempo en las Escuelas de Jornada Ampliada de la República Dominicana. Washington: The World Bank, 2012. Disponível em: http://sitios.educando. edu.do/revisioncurricular/data/uploads/gineida-2/2012-reporte-uso-del-tiempo_rdominicana-v2.pdf. Acesso em: 22 abr. 2015.

URUGUAY. Ministerio de Educación y Cultura. Avances y problemas de la educación uruguaya: 15 avances, 7 desafíos y acciones para el 2014. Sesión de la Comisión Permanente del Poder Legislativo, feb. 2014. Disponível em: http://www.mec.gub.uy/ innovaportal/file/46704/1/avances__y_desafios_de_la_educacion_uruguaya_11_de_ febrero_de_2014_mec.pdf. Acesso em: 22 abr. 2015.

Profa. Dra. Andréa Giordanna Araujo da Silva

Universidade Federal de Alagoas

Centro de Educação

Grupo de Pesquisa História da Educação, Cultura e Literatura E-mail|agiordanna@hotmail.com

Recebido 15 ago. 2017

Aceito 6 out. 2017 